\title{
UMA ANÁLISE DA PRÁTICA DIÁRIA DE PACHO FLORES: AQUECIMENTO E ESTUDOS TÉCNICOS PARA TROMPETE
}

AN ANALYSIS OF PACHO FLORES DAILY PRATICE: WARM-UP AND TECHNICAL STUDIES FOR TRUMPET

Flávio Gabriel ${ }^{1}$

Universidade Federal do Rio Grande do Norte (UFRN) contato@flaviogabriel.com.br

Clayton Vetromila Universidade Federal do Estado do Rio de Janeiro (Unirio) cvetromilla@gmail.com 


\section{Resumo}

O presente artigo apresenta alguns conceitos utilizados por Pacho Flores em sua prática diária do trompete, relaciona-os aos métodos tradicionais e compara-os à prática realizada por trompetistas brasileiros. Além de gravar e transcrever os exercícios apresentados por Pacho Flores durante o 5을 Festival Internacional Sesc de Música, realizou-se uma pesquisa on-line com grupo de trompetistas profissionais e estudantes brasileiros a respeito de suas práticas diárias. As conclusões apontam os possíveis benefícios que um trompetista pode obter ao manter uma prática diária como a de Pacho Flores e, além disso, motivaram a elaboração de um método autoral para a divulgação das ideias desse renomado trompetista.

Palavras-chave: Trompete; exercícios de aquecimento; estudos diários.

\section{Abstract}

The present article presents some concepts utilized by Pacho Flores during his daily pratice on the trumpet, relate them to the tradicional methods and compare them to the pratice realized by brazilian trumpet players. Besides recording and transcribing the exercises presented by Pacho Flores at the 5은 SESC International Music Festival, an online research was made with a group of a professionals and students brazilian trumpet players about their own daily pratices. The conclusions point to the possible benefits that a trumpet player could obtain while keeping a daily pratice alike Pacho Flores' and besides that, motivated the elaboration of an autoral method in order to promote the ideas of this renowed trumpet player.

Keywords: Trumpet; warm-up exercices; daily pratice.

\footnotetext{
1 Flávio Gabriel é professor de trompete na Escola de Música da Universidade Federal do Rio Grande do Norte (UFRN), doutor em Música pela Universidade Estadual Paulista (Unesp) e presidente da Associação Brasileira de Trompetistas (ABT). Foi o principal trompetista da Orquestra Sinfônica de Porto Alegre (Ospa), entre 2004 e 2009, e membro da Orquestra Sinfônica do Estado de São Paulo (Osesp), entre 2009 e 2015. Em 2010 foi premiado no $61^{\circ}$ Concurso Internacional de Música Primavera de Praga. Desde então, tem atuado como solista em diversas orquestras no país e no exterior.

2 Clayton Vetromilla é professor no Instituto Villa-Lobos da Universidade Federal do Estado do Rio de Janeiro (Unirio). Atuou na Escola de Música da Universidade do Estado de Minas Gerais (Uemg) e no Conservatório de Música da Universidade Federal de Pelotas (UFPel). É bacharel em Música (Instrumento: Violão) pela Universidade Federal de Minas Gerais (UFMG), mestre em Música/Práticas Interpretativas pela Universidade Federal do Rio de Janeiro (UFRJ) e doutor em Música pelo PPGM da Unirio.
} 


\section{Introdução}

O venezuelano Pacho Flores é oriundo do projeto El Sistema (Sistema Nacional de Orquestras) e atuou como principal trompetista por mais de vinte anos na Orquestra Sinfônica Juvenil Simón Bolivar. Concebido e fundado pelo maestro José Antônio Abreu no ano de 1975, o projeto, partindo do pressuposto de que a música atua positivamente como mecanismo de organização social e desenvolvimento humanístico, objetiva fornecer a instrução e possibilita a prática coletiva e individual da música por meio de orquestras sinfônicas e coro ${ }^{3}$. A carreira de Pacho Flores como solista internacional teve início no ano de 2006, ao vencer a competição mais conceituada entre os trompetistas profissionais da atualidade, o concurso Maurice André.

Após se tornar um artista exclusivo do selo Deutsche Grammophon, Pacho Flores tem se destacado como um dos principais trompetistas internacionais, requisitado também como professor em inúmeros festivais. Em janeiro de 2015, ele foi um dos professores do 5을 Festival Internacional Sesc de Música, na cidade de Pelotas, no Rio Grande do Sul, permitindo que seus ensinamentos fossem documentados para a análise a que este estudo se propõe. Sendo assim, o presente artigo tem como objetivo descrever os exercícios básicos que Pacho Flores pratica durante o período inicial de seus estudos diários ("aquecimento").

Durante o referido curso, as aulas eram ministradas no período matutino, entre $9 \mathrm{~h}$ e $12 \mathrm{~h}$, para um grupo de doze alunos, selecionados entre setenta inscritos vindos de todo o País. O material utilizado nesta análise compreende o assunto abordado diariamente em cada primeira hora de aula, ou seja, durante as etapas de aquecimento e de estudos técnicos realizados coletivamente. Todas as aulas foram filmadas, e os exercícios apresentados em classe foram transcritos no programa "Finale", compondo um corpus consistente de material didático e pedagógico.

Para efeito de comparação, além de mencionar exercícios que, extraídos de métodos de trompete tradicionais, estão relacionados à prática de Pacho Flores, realizou- se uma pesquisa sobre a prática de estudos de trompetistas brasileiros, profissionais e estudantes. Para tal, três questionários on-line foram elaborados, abordando questões a respeito da prática diária do instrumento pelos envolvidos. A primeira com um grupo de trompetistas brasileiros profissionais, a segunda com estudantes, e a última com o próprio Pacho Flores ${ }^{4}$.

O grupo de profissionais respondeu ao mesmo questionário enviado para os estudantes, acrescido de uma pergunta sobre uma análise dos exercícios realizados por

\footnotetext{
3 Disponível em: http://fundamusical.org.ve/el-sistema/. Acesso em: 24 maio 2015. De acordo com o site oficial do El Sistema na Venezuela, mais de 700 mil jovens são atendidos por esse projeto social. Disponível em: http://fundamusical.org.ve/category/el-sistema/impacto-social/. Acesso em: 24 maio 2015.

4 Dez questões foram elaboradas visando extrair um quadro geral a respeito da prática diária do trompete. São elas: Você estuda trompete diariamente? Qual a duração dessa atividade? Você realiza algum tipo de aquecimento com o trompete? Qual a duração dessa atividade? Você diferencia o seu aquecimento do seu estudo no instrumento? Quais métodos costuma utilizar em seus estudos diários? Pratica vibração labial sem bocal? Pratica vibração labial com bocal? Pratica notas pedais? Por favor, escreva abaixo suas considerações quanto ao material enviado em anexo. Você pratica algo parecido?
} 
Pacho Flores. Para isso, foi enviado - via e-mail ou mensagem da rede social Facebook - um arquivo com parte dos exercícios transcritos. Todas as questões foram respondidas anonimamente; no entanto, alguns profissionais se identificaram ao enviar e-mails ou mensagens instantâneas para realizar comentários e/ou sugestões. As questões enviadas a Pacho Flores tiveram o intuito de obter informações a respeito de sua prática diária que não puderam ser visualizadas no material filmado.

O grupo de profissionais contou com 40 trompetistas brasileiros, músicos de orquestras como a Orquestra Sinfônica do Estado de São Paulo, a Orquestra Sinfônica de Porto Alegre, a Orquestra Filarmônica de Minas Gerais, a Orquestra Sinfônica da Bahia, a Orquestra Sinfônica do Paraná, a Banda Soundscape e a Banda Mantiqueira, bem como professores de trompete de diversas universidades brasileiras. O grupo de trompetistas estudantes contou com a participação de 26 estudantes de nível universitário, alunos de conservatório, de festivais e alunos particulares.

\section{Aspectos da trajetória de Pacho Flores}

Embora o objetivo desse artigo seja o de apresentar uma análise sobre a prática diária de Pacho Flores, um breve histórico a respeito dos processos de formação do artista, bem como o modo com que ele tem conduzido sua carreira como solista internacional, visa destacar a importância deste trompetista no cenário internacional da música de concerto.

Nascido em 1981 na cidade de São Cristovão (Venezuela), o trompetista Francisco (Pacho) Colmenares Flores cresceu cercado de instrumentos musicais, iniciando seus estudos no trompete aos sete anos em sua própria casa, com seu pai. Ainda de acordo com Pacho, desde muito cedo, teve contato com diversos estilos musicais, passando pelo merengue, salsa e porro, que faziam parte do repertório da orquestra de baile conduzida por seu pai, bem como com o repertório sinfônico e popular composto para bandas, pois seu pai era maestro da banda sinfônica da cidade de Táriba, próxima à São Cristovão (MCKEY, 2013).

Após alguns anos, Pacho passou a estudar com Orlando Paredes na escola de música Miguel Ángel Espinel, em sua cidade natal. Conforme Pacho, seu pai continuou atuando como seu professor, principalmente na orientação quanto a teoria musical, solfejo e harmonia. Pacho atribui a seu pai a influência para que se tornasse um solista, por ter crescido ouvindo discos dos renomados trompetistas Maurice André, Al Hirts, Harry James, Arturo Sandoval. Aos 15 anos de idade, Pacho ingressou no El Sistema.

Após uma audição organizada pelo trompetista Jairo Hernandez, o maestro José Antonio Abreu tratou de convencer os pais de Pacho para que ele se mudasse para a capital Caracas, podendo assim integrar o quadro da Orquestra Sinfônica Juvenil Simón Bolívar. Uma vez dentro do El Sistema, Pacho teve acesso a grandes professores do instrumento, como Rolf Smedvig, Frank Puccini e Max Sommerhalder. Como principal trompetista da orquestra, participou de diversas turnês internacionais, trabalhando com maestros como Claudio Abbado e Simon Rattle. À época, um de seus principais profes- 
sores foi o trompetista Eduardo Manzanilla. Pacho explica a importância do El Sistema e a revolução que esse projeto trouxe para o ensino na música em seu país:

\begin{abstract}
Uma criança nasce com algum talento, mas o talento de cada um merece o apoio de condições externas. E aí entra em minha vida o Sistema Nacional de Orquestras, que já tem quase quarenta anos formando seres integrais a partir da música. Temos demonstrado que dar concertos é tão importante como os ensaios, e isso transforma a maneira de ensinar música no mundo. Antes uma criança passava por um processo de lições, provas, depois pelo conservatório e não era até que se formasse que começava a buscar um lugar em uma sinfônica. Agora essa mesma criança agarra o trompete aos sete anos de idade, quando já tem os dentes mudados e está anatomicamente pronto, e em meses já está incorporado em uma orquestra infantil, com professores que têm responsabilidades paralelas de formá-lo tecnicamente e na orquestra. Por isso, nosso nível subiu tanto e tem bases tão sólidas. Quando estava em Paris me especializando para ser solista, pude fazê-lo porque na Venezuela tive minha formação orquestral. Tudo o que um estudante adquire em quatro, cinco e até seis anos, os nossos já têm em um ano. Há aqueles que ainda não acreditam, mas também existem países que querem copiar o sistema ${ }^{5}$.
\end{abstract}

Em 2003, aos 22 anos de idade, Pacho participou do 5 Concurso Internacional Maurice André, em Paris. Após não ter sido aprovado para a segunda fase do concurso, ele decidiu mudar para Paris com o intuito de poder se especializar como solista. Em 2004 Pacho passa a estudar com o solista internacional Eric Aubier no Conservatório Nacional da Região de Vila de Rueil-Malmaison. A mudança surtiu efeito e, entre os anos 2005 e 2006, Pacho venceu diversos concursos internacionais de trompete, como o Concurso Internacional de Trompete Philipe Jones, na cidade de Guebviller, na França, ○ 6을 Concurso Internacional de Trompete Maurice André e o Concurso Internacional de Trompete Citta di Porcia, na Itália.

Em 2013 Pacho passa a viver em Valência, Espanha, com o objetivo de facilitar suas viagens pela Europa e estar mais próximo de seu mentor, Vicente Honorato. Vicente é o fundador da fábrica de instrumentos de metal Stomvi, marca dos instrumentos que Pacho escolheu para utilizar desde o final de sua adolescência. Os dois se conheceram em 2001 e começaram a trabalhar juntos quando Pacho foi à França estudar com Eric Aubier. Além de trabalharem na construção de instrumentos, Vicente, apesar de não ser músico, também passou a atuar como professor de Pacho, como é possível acompanhar em seu relato:

5 Disponivel em: http://historico.prodavinci.com/2013/08/26/artes/pacho-flores-uno-de-los-mejores-trompetistas-del-mundo-es-venezolano-por-willy-mckey/. Acesso em: 28 jul. 2019. Todas as traduções foram realizadas pelo autor do presente texto. No original: "Uno desde niño nace con algún talento, pero el talento de cada quien merece un apoyo de las condiciones externas. Y ahí entra en mi vida el Sistema Nacional de Orquestas, que ya tiene casi cuarenta años formando seres integrales a partir de la música. Hemos demostrado que dar los conciertos es tan importante como los ensayos y eso ha transformado la manera de enseñar música en el mundo. Antes un niño pasaba por un proceso de lecciones, exámenes, luego por el conservatorio y no era sino hasta que se graduaba que empezaba a buscar lugar en una sinfónica. Ahora ese mismo niño agarra la trompeta a los siete años, cuando ya tiene los dientes mudados y está anatómicamente listo, y a los meses ya está incorporado en una orquesta infantil, con profesores que tienen las responsabilidades paralelas de formarlo técnicamente y con la orquesta. jPor eso nuestro nivel ha subido tanto y tiene bases tan sólidas! Cuando estaba en París especializándome porque quería ser concertista, pude hacerlo porque en Venezuela tuve mi formación orquestal. Todo lo que un estudiante adquiere en cuatro, cinco y hasta seis años, los nuestros lo tienen en un año. Hay quienes aún no se lo creen, pero también hay países que quieren copiar el Sistema". 
A intensidade de trabalho [com Vicente Honorato] e a conexão que temos conseguido é bárbara, pois em nenhum outro lado eu teria podido trabalhar tão perto da construção. Fizemos trompetes em apenas 24 horas, mas não se trata apenas de aspectos técnicos: Vicente é uma pessoa com um ouvido privilegiado que, sem ser músico, tem me dado as melhores aulas de trompete; isso tem a ver com sua maneira tão singular de desfrutar da música. Há muita confiança e trabalho por trás de cada instrumento: Devo ser muito específico sobre o que incluir e o que tirar, pois temos feito trompetes para conseguir um só efeito... um matiz específico para uma obra apenas. No disco para Deustche Grammophon, gravei com nove trompetes diferentes, cada um com suas características particulares ${ }^{6}$.

Se no disco Cantar Pacho utilizou nove trompetes, incluindo um corno da caccia na interpretação do concerto de Johann B. G. Neruda, foi a partir de 2015 que ele expandiu suas possibilidades técnico-interpretativas ao utilizar todos os seus trompetes com quatro pistões. Embora o uso de quatro pistões já fosse usual no caso dos trompetes piccolos e até mesmo no flugelhorn, quatro pistões não são comuns em trompetes maiores, como os de tonalidades em si bemol e dó, por exemplo. Com toda uma linha de trompetes com uma extensão maior, as transcrições realizadas por Pacho passam a explorar diversos matizes do repertório. O próprio artista explicou em uma entrevista:

Com o trompete de quatros pistões, podemos fazer as linhas melódicas perfeitas, como foram concebidas. Não é necessário fazer falsas resoluções melódicas. Dá uma sensação totalmente orgânica, que é o que eu sentia falta nos arranjos anteriores. Quando se está subindo e baixando oitavas, quem conhece a obra tem esse problema, percebe essas mudanças; agora temos conseguido o objetivo de sermos fiéis à obra?

A expansão não ocorre somente em termos de instrumentos. Assim como os demais solistas dessa pesquisa, Pacho também trabalha o repertório de compositores contemporâneos com o intuito de expandir a produção para trompete. Essa série de inovações marca o início do 4ำ estágio de desenvolvimento de Pacho de acordo com as diretrizes apontadas por Ericsson (2016). Em outubro de 2010, Pacho estreia a obra Mestizo, do compositor Efrain Oscher, a primeira de uma série de obras dedicadas ao artista por compositores latino-americanos. Fazem parte da lista: concertos compostos para trompete e orquestra por compositores como Paquito D'Rivera, Roberto Sierra e Arturo Márquez. Atualmente Pacho Flores tem estudado composição e regência com orientação do trombonista, maestro e compositor Cristian Lindberg.

\footnotetext{
6 Disponivel em: http://historico.prodavinci.com/2013/08/26/artes/pacho-flores-uno-de-los-mejores-trompetistas-del-mundo-es-venezolano-por-willy-mckey/. Acesso em: 29 jul. 2019. Original: "La intensidad de trabajo y la conexión que hemos logrado es bárbara, pues en ningún otro lado yo habría podido trabajar así de cerca de la construcción. Hemos hecho trompetas en apenas veinticuatro horas, pero no se trata sólo de los aspectos técnicos: Vicente es una persona con un oído privilegiado que, sin ser músico de estudio, me ha dado las mejores lecciones de trompeta de mi vida y eso tiene que ver con su manera tan singular de disfrutar la música. Hay mucha confianza y trabajo detrás de cada instrumento: debo ser muy específico sobre qué añadir o qué quitarle, pues hemos hechos trompetas para lograr un solo efecto... un matiz específico para sólo una obra. En el disco para Deutsche Grammophon grabé con nueve trompetas diferentes, cada una con sus características particulares".

7 Disponivel em: https://www.diariodesevilla.es/mapademusicas/Pacho_Flores-entrevista_0_1302770158.html. Acesso em: 29 jul. 2019. Original: "Con la trompeta de cuatro pistones podemos hacer líneas melódicas perfectas, como fueron concebidas. No hace falta hacer falsas resoluciones melódicas. Da una sensación totalmente orgánica, que es lo que a mí me faltaba en los arreglos anteriores. Cuando estás subiendo y bajando octavas, el que conoce la obra tiene ese problema, que nota que estás cambiando cosas; aquí hemos conseguido el reto de ser fieles a la pieza".
} 


\section{O estudo diário e seus aspectos}

A pesquisa realizada aponta que o estudo diário do instrumento é prática comum entre músicos profissionais e estudantes que pretendem se profissionalizar. Dentre os trompetistas pesquisados, $100 \%$ dos estudantes e $94,87 \%$ dos profissionais informaram estudar trompete diariamente ou com apenas um dia de descanso. Essa atividade tem duração de até três horas diárias para $80 \%$ dos profissionais e de quatro horas ou mais para $58 \%$ dos estudantes. A importância de tal prática é explicada pelo professor Naílson Simões: "Sabe-se que este treinamento diário é necessário para o desenvolvimento técnico-interpretativo e, ao mesmo tempo, para a manutenção do condicionamento físico do instrumentista. Esta prática é de suma importância para a evolução do praticante" (SIMÕES, 2001, p.38).

Pacho Flores está entre aqueles que estudam trompete diariamente e, durante os cinco dias em que foi observado, demonstrou extrema dedicação, disciplina e seriedade na prática de seu instrumento. Com sessões de estudo que variaram de uma hora a uma hora e meia, Pacho Flores aborda princípios básicos de alongamento corporal, exercícios de respiração e uma série de estudos técnicos, praticados com o objetivo de se "manter em forma" e também de se desenvolver tecnicamente ${ }^{8}$.

Pacho Flores tem como hábito praticar até três horas diariamente ${ }^{9}$, dividindo esse período em um terço para aquecimentos e estudos técnicos e dois terços para a preparação de repertório. Para essa atividade, ele se utiliza de exercícios que, apesar de não estarem editados em livros, são frequentemente utilizados por grandes professores, como, por exemplo, as inúmeras e riquíssimas variantes criadas a partir de exercícios extraídos de métodos tradicionais (Warm-ups and studies, de James Stamp, 1978, e Technical studies for the cornet, de Herbert Lincoln Clarke, 1912), além de criações próprias, por ele mesmo (Pacho Flores) elaboradas. Desta maneira, todo o registro do instrumento e os mais diversos tipos de articulações são contemplados.

Os dois métodos citados estão entre os quatro mais utilizados entre os trompetistas entrevistados em nossa pesquisa; $86 \%$ dos estudantes e $85 \%$ dos profissionais afirmam utilizar o método elaborado por Jean Baptiste Arban (1825-1889) - Complete method: trumpet. Herbert L. Clarke é utilizado por $68 \%$ dos estudantes e por $51 \%$ dos profissionais. Max Schlossberg (1875-1936) - Daily drills and technical studies for trumpet - é praticado por $54 \%$ dos profissionais e por $45 \%$ dos estudantes, enquanto James Stamp, por $36 \%$ dos estudantes e por $27 \%$ dos profissionais.

Em linhas gerais, Pacho Flores aplica aos exercícios da técnica tradicional (escalas e arpejos, por exemplo) variações rítmicas e de tonalidades. Ele também parte de diversas escalas e arpejos para criar novos exercícios que lhe servem, ora como prática para mantê-lo "em forma", ora para expandir sua técnica, seja de velocidade de dedilhados,

\footnotetext{
80 período analisado na pesquisa compreende apenas a parte de aquecimento e os estudos técnicos; portanto, o estudo de repertório não foi contabilizado.

9 Todas as informações do trompetista Pacho Flores apresentadas neste texto foram extraídas de uma pesquisa on-line respondida por ele. Os trechos citados desta entrevista serão lançados neste artigo, com a indicação (FLORES, Pacho).
} 
golpes de língua ou expansão do seu registro atual.

Tal variedade é tão constante que, durante os cinco dias em que acompanhamos o processo de estudo, nenhum exercício apresentado foi repetido.

\section{Sonoridade}

Diariamente, antes mesmo dos primeiros exercícios de aquecimento serem apresentados, Pacho Flores explica que o processo de produção do som se inicia antes de se soprar. Para ele, trata-se de um processo mental-físico no qual a idealização do som desejado e a confiança que se vai alcançar tal som são uma premissa básica para que o corpo se encarregue de produzi-lo. Esse conceito é aplicado por ele toda vez que apresenta um exercício diferente. Em suas aulas, ele costuma apresentar o exercício tocando-o ao trompete e, depois, solicitando que os presentes repitam o exercício que ele acabara de fazer.

No início, não há nenhuma instrução verbal, apenas o seu exemplo sonoro repetido por duas ou três vezes. Após isso, quando necessário, ele sugere que os estudantes o escutem com mais atenção, imaginando a sonoridade para depois reproduzir o exercício com as mesmas qualidades por ele apresentadas. Se depois de algumas tentativas os alunos não alcançarem reproduzir o exercício de maneira satisfatória, Pacho oferece diretivas específicas, alertando sempre para a necessidade de ouvir com atenção.

\section{Aquecimento e estudos técnicos}

$\mathrm{O}$ ato de tocar um instrumento é frequentemente comparado por Pacho Flores à prática de atividade esportiva; frequentemente, através de comparações ou metáforas, ele apresenta inúmeras semelhanças entre tais práticas. A finalidade do aquecimento é:

[...]Entende-se por aquecimento todas as medidas que servem como preparação para a atividade, seja para o treinamento ou para competição, cuja intenção é a obtenção do estado ideal físico e psíquico bem como preparação cinética e coordenativa na prevenção de lesões (ALENCAR; MATIAS, 2010, p.230).

Neste estudo, ficou constatado que $100 \%$ dos profissionais e $96,15 \%$ dos estudantes realizam algum tipo de aquecimento com o trompete. Foi constatado, no entanto, que existe certa dificuldade em diferenciar tal atividade (o aquecimento) dos estudos técnicos. Apenas 58,97\% dos profissionais e 52\% dos estudantes afirmam fazer essa diferenciação, reforçando a ideia de que muitos trompetistas não possuem um conceito claro quanto aos objetivos de seus estudos. Simões também alerta a respeito dessa dificuldade:

O aquecimento é uma etapa importante do estudo diário, na qual nos preparamos para o trabalho determinado. Muito cuidado com o aquecimento: vários trompetistas profissionais, ao chegar ao fim de seu aquecimento, já estão cansados fisicamente e até mesmo psicologicamente. A criatividade deve estar sempre presente em qualquer ocasião, para que a prática nunca se torne uma rotina enfadonha. (SIMÕES, 2001, p.38). 
Embora os exercícios apresentados por Pacho Flores estejam em sequência e compreendam um período de uma hora aproximadamente, ele afirma que diferencia a fase de aquecimento da fase dos estudos técnicos, sendo que a primeira tem duração média de 15 a 20 minutos. Todas as aulas iniciam com exercícios de alongamento corporal, com atenção especial ao pescoço, ombros e braços, membros normalmente sobrecarregados na prática do trompete. Enquanto os alunos repetiam os exercícios realizados, Pacho salienta a importância da prática regular desses alongamentos com o intuito de evitar lesões e também de aquecer o corpo para o trabalho que está por vir.

Nesta etapa, Pacho Flores apresenta um exercício de respiração que, embora simples, contém diversos conceitos de ordem musical - por exemplo, o ritmo, a duração e a sustentação do ar (Fig. 1). Para o exercício, com o auxílio de estalos dos dedos, ele marca um compasso quaternário com tempo aproximado à semínima, equivalente a $78 \mathrm{bpm}$. Depois, inala uma grande quantidade de ar no quarto tempo do compasso e o expele, soprando em três semínimas, com os cantos dos lábios fechados quase como se fosse realizar uma vibração labial, porém deixando a parte central dos lábios aberta, de maneira que não seja possível vibrá-los. Pode-se ouvir no som produzido pela passagem de ar uma articulação bastante firme no início de cada semínima, mas também se nota que a passagem de ar sofre apenas a separação dessa articulação, sem espaço entre elas, dando a ideia de passagem de ar intensa e constante.

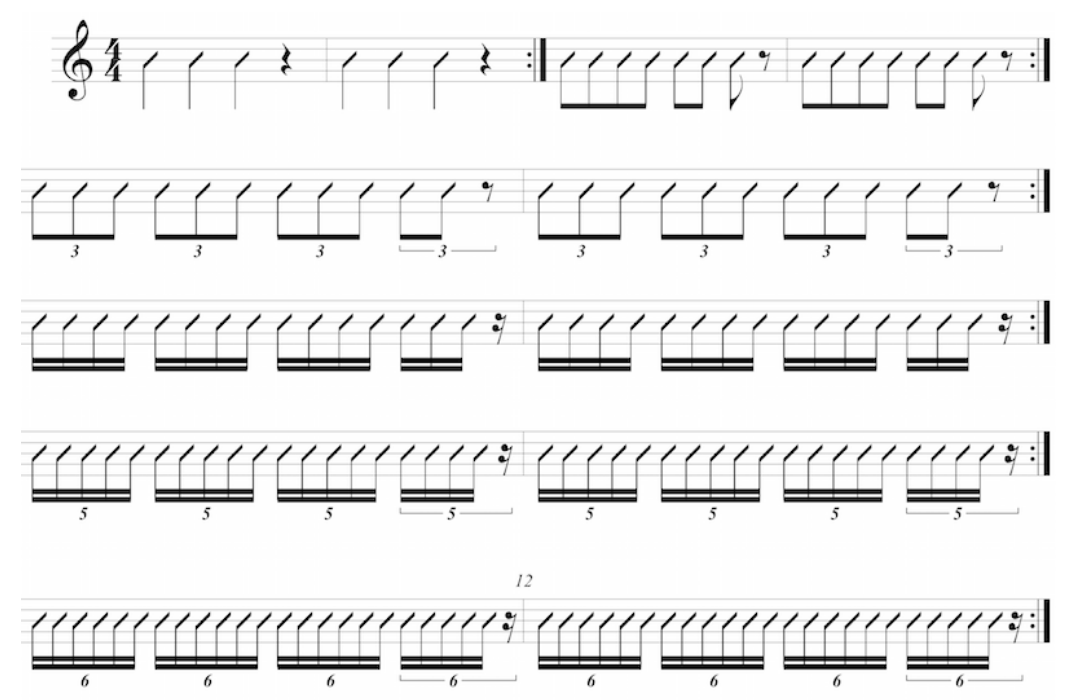

Fig. 1: Exercício de respiração.

Fonte: Notações musicais feitas pelo autor. 


\title{
Vibração labial ${ }^{10}$
}

Pacho Flores é adepto da prática da vibração labial sem bocal, bem como da vibração labial apenas com o bocal, e inclui em sua prática diária alguns exercícios bastante complexos, se comparados a outros métodos tradicionais. O famoso professor de trompete Claude Gordon (1916-1996), autor dos livros Systematic Approach to Daily Pratice e Physical Approach, é totalmente contrário a qualquer uma dessas práticas, como se observa a seguir:

\begin{abstract}
A única função dos lábios é vibrar. A velocidade de ar e a posição da língua são a causa, e a vibração dos lábios o efeito. Os lábios devem estar flexíveis e capazes de responder facilmente. Deve-se tomar cuidado para não abusar dos lábios e dificultar a vibração livre. Evite qualquer tipo de abelhinha com o propósito de adquirir resistência. (PURTLE, 2014) ${ }^{11}$.
\end{abstract}

É neste tipo de prática que se encontra a maior diferença entre os estudos realizados por Pacho Flores e os estudos realizados pelos trompetistas profissionais que foram objeto da presente pesquisa. A seguir, discute-se aspectos das duas maneiras de se praticar vibração labial.

\section{Vibração labial sem bocal}

A respeito dessa prática, o trompetista virtuoso Allen Vizzutti (n. 1952), autor do livro The Allen Vizzutti Trumpet Method, afirma: "Vibrar seus lábios sem bocal pode ser relaxante e benéfico. Eu apenas não toco trompete dessa maneira. São atividades distintas" (VIZZUTTI, 2012) ${ }^{12}$. Por sua vez, o professor James Thompson (n. 1949), que ocupou a função de principal trompetista da Orquestra Sinfônica de Montreal, da Orquestra Sinfônica de Atlanta, é autor do livro Buzzing Basics, dá a seguinte justificativa: "Pode ter seus méritos, mas eu não faço isso. Estou tentando treinar os músculos da embocadura na posição que eles devem estar quando toco normalmente" (THOMPSON, 2015). ${ }^{13}$

Entre os trompetistas brasileiros, a opinião é dividida: $50 \%$ dos profissionais entrevistados não praticam vibração labial sem o bocal, enquanto outros $25 \%$ afirmam que o fazem (a prática da vibração labial sem o bocal) por, no máximo, um minuto. Entre os estudantes, no entanto, apenas $20 \%$ se declararam não praticantes dessa atividade, ou seja, $80 \%$ deles pratica a vibração labial sem o bocal. Segundo Pacho Flores, apesar da produção do som no trompete ser completamente diferente, a prática desses exercícios

\footnotetext{
10 Ato realizado com a contração dos cantos da boca e a parte central dos lábios superior e inferior em contato, mas livres para vibrar com a passagem de ar. No Brasil, utilizamos as palavras abelhinha ou besouro como tradução do termo em inglês buzzing, referência ao som emitido que é parecido com o produzido por esses insetos.

11 Original: "The lips' only function is to vibrate. Wind power and tongue level are the cause, and the vibration of the lips is the effect. The lips must be flexible and able to respond easily. Care must be taken to not abuse the lips, and hindering their free vibration. Avoid buzzing of any kind, tight mouthpieces and long tones for the purpose of building strength".

12 Original: "Buzzing your lips without the mouthpiece can be relaxing and beneficial. I just don't play the trumpet that way. It's a separate deal".

13 Original: "It may have its merits but I don't use it. I'm trying to train the embouchure muscles in the position they must be in normal playing".
} 
gera inúmeros benefícios, se bem administrada:

Pratico porque é um exercício que nos dá muitas pistas para compreender os problemas. Evidentemente não é a mesma vibração daquela quando colocamos os lábios no bocal, mas é um treinamento parecido com um aquecimento muscular. É simplesmente pensar que somos esportistas de elite e devemos buscar exercícios complementares e lógicos para poder aplicar ao trompete. (FLORES, Pacho).

James Stamp é um dos poucos autores a mencionar a prática de vibração labial sem bocal. Em seu livro Warm-ups and Studies, ele sugere um início básico (Fig. 2):

Quando iniciam apenas com os lábios, muitas pessoas não podem ir muito agudo. Comece com um DÓ grave e segure por vários tempos, então vá do DÓ ao DÓ\#. Continue adicionando meios tons conforme os lábios forem fortalecendo até chegar a nota SOL. Alguns gostam de ir o mais agudo possível, mas tente pelo menos ir até o DÓ médio (STAMP, 1995, p.5). ${ }^{14}$

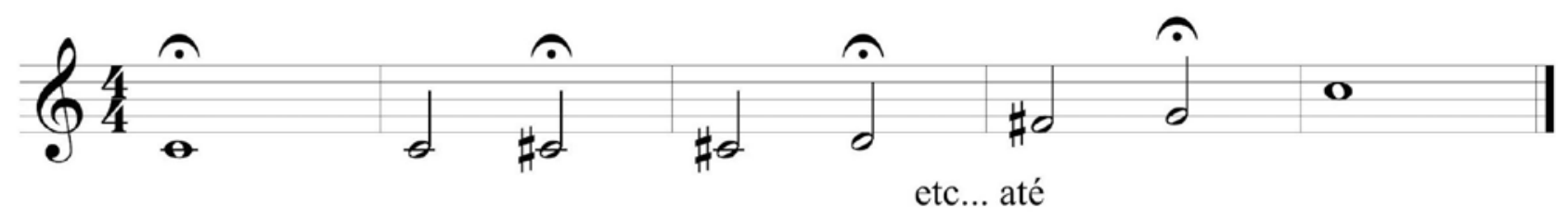

Fig. 2: Exercício sugerido por James Stamp.

Fonte: Notações musicais feitas pelo autor.

A elaboração de Pacho Flores vai muito além de exercícios básicos (Fig. 3, 4 e 5). Eles são repetidos diversas vezes na direção descendente, por tons inteiros e com variações rítmicas. Dependendo do dia, a execução de uma série de exercícios de vibração labial sem bocal proposta por Pacho Flores tem duração entre cinco e 15 minutos.

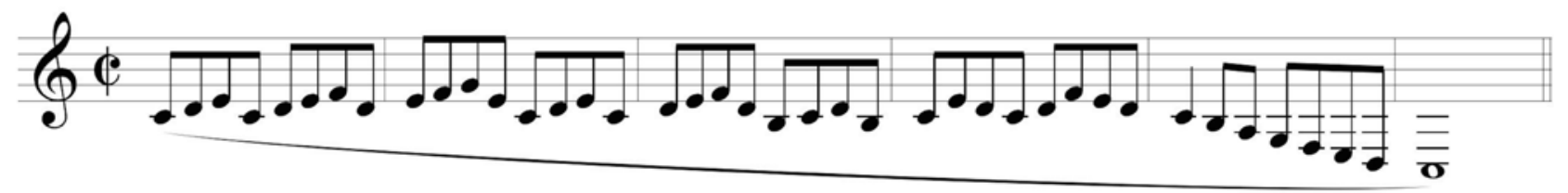

Fig. 3: Baseado no exercício nº 2 de H. Clarke (1912) com pequena variação ao final. Fonte: Notações musicais feitas pelo autor.

14 Original: "When starting on lips alone, many people can't get very high. Start on low C and hold for several counts (6 to 8) then go from C to $\mathrm{C} \#$ in half tones. Keep adding half-tones as the lips strengthens until middle $\mathrm{G}$ is reached. Some like to go as high as possible, but at least try to go to middle $C^{\prime \prime}$. 


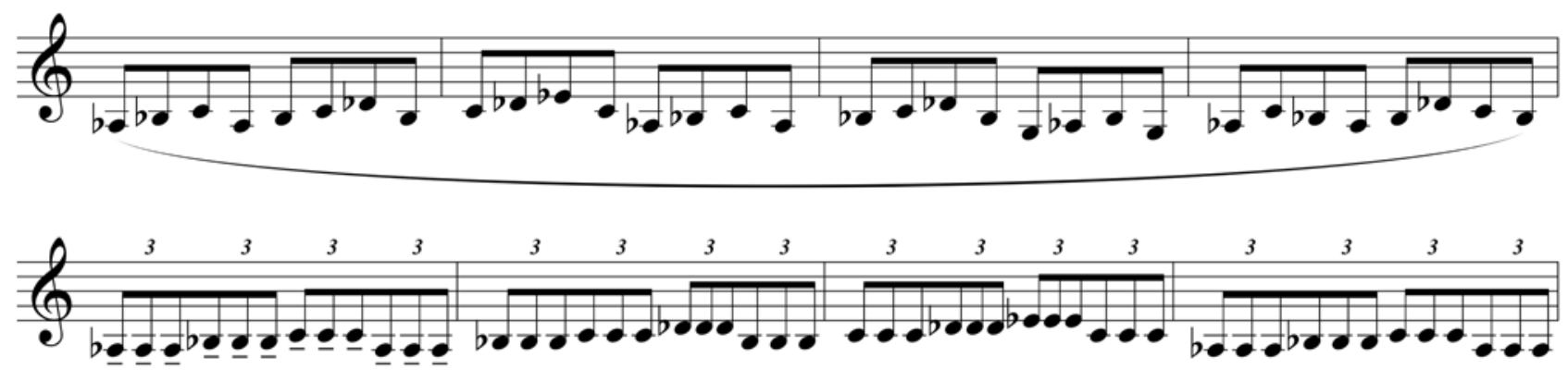

Fig. 4: Baseado no exercício nº 2 de H. Clarke (1912) com variações rítmicas. Notações musicais feitas pelo autor.

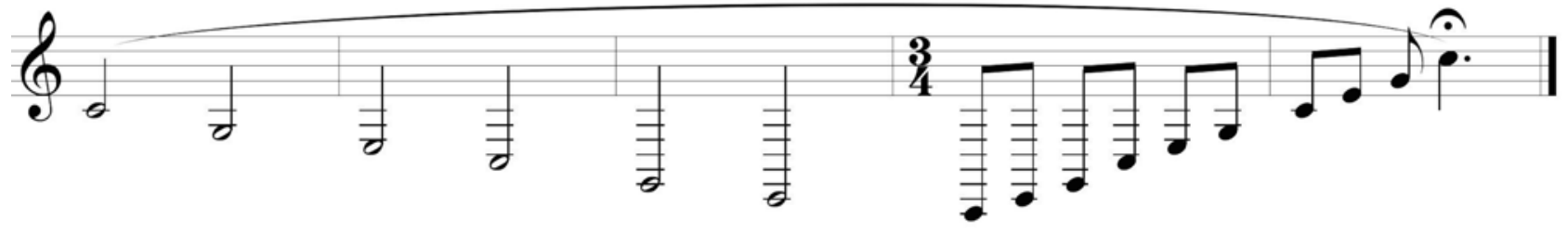

Fig. 5: Exercício de vibração labial com conexão entre Dó 1 e Dó 4.

Fonte: Notações musicais feitas pelo autor.

Ao começar o exercício, Pacho Flores confere, no trompete, a altura correta da nota inicial e, muitas vezes, enquanto os alunos repetem o exercício, os acompanha, tocando a melodia no instrumento para que possam se certificar de que estão sendo emitidas as alturas correspondentes. Assim como nos exercícios de respiração, Pacho Flores adverte que os estudantes devem manter um fluxo contínuo de ar e não "cortar" as notas, pois, desta maneira, segundo ele, pode-se perceber o ar fluindo e, sobretudo, estarem relaxados.

Ele afirma ainda que: "Quando pratico vibração labial, penso que o som não deve partir dos lábios, e sim do corpo. Os lábios funcionam como amplificadores" (FLORES, Pacho). Ciente de que está habituado a trabalhar em um registro não usual para a maioria dos trompetistas, Pacho Flores, com um grande sorriso no rosto, durante as aulas, perguntava aos estudantes como eles se sentiam ao visitar o "inframundo".

\section{Vibração com bocal}

A prática de estudos de vibração labial com bocal é muito melhor aceita pela comunidade de trompetistas de modo geral e pode ser observada também entre os trompetistas brasileiros: $81,08 \%$ dos profissionais e $94 \%$ dos estudantes praticam "abelhinha" com bocal. O professor Thompson, autor do livro Buzzing Basic, embora contrário à prática da vibração labial sem bocal, é um entusiasta da vibração labial com bocal. Segundo ele:

Abelhinha com o bocal tem vários benefícios se realizado sistematicamente e com uma abordagem observadora. Como o bocal oferece menos resistência que o instrumento, a abelhinha ajuda o trompetista a se habituar a utilizar mais ar. Esse grande fluxo de ar ajuda a deixar os lábios relaxados e vibrar mais livre- 
mente, produzindo um som mais ressonante (THOMPSON, 2015) ${ }^{15}$.

É importante ressaltar que o processo de produção de som da "abelhinha" com bocal, ao contrário de sua versão sem bocal, deve ser muito próximo ou idêntico ao processo de produção de som no instrumento. Allen Vizzutti adverte:

Tocar com o bocal é ótimo e pode ser de grande ajuda na melhora do som, tocar relaxado e aquecer... Mas eu toco com o bocal, eu não faço abelhinha dentro dele, embora saia um som de abelhinha através dele. Há uma confusão, porque eu venho ensinando "Sopre, não vibre" por anos... Se você fizer abelhinha com seus lábios para tocar, seu som será como o de um iniciante ou de um gato sufocado com uma bola de pelos depois de fumar um pacote de cigarros (VIZZUTTI, $2012)^{16}$.

Pacho Flores possui um conceito parecido: "Porque, quanto melhor soe com o bocal, melhor soará com o trompete" (FLORES, Pacho). Os exercícios de vibração labial com bocal que foram elaborados por Pacho Flores também trabalham com tessituras extremas, mas, assim como em quase todos os exercícios praticados por ele durante seu aquecimento, sempre iniciam no registro médio do instrumento (entre Dó3 e Dó4) e vão expandindo, tanto para o registro agudo como para o grave (Fig. 6).

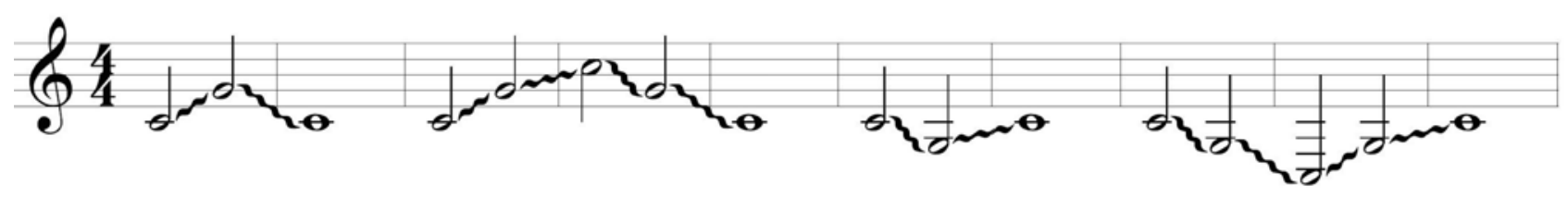

Fig. 6: Exercícios iniciais de vibração labial com bocal. Fonte: Notações musicais feitas pelo autor.

O objetivo dos glissandi é fazer com que o executante possa observar a conexão das diversas alturas e contrair ou relaxar os lábios da maneira mais eficiente. As partes com glissando são realizadas com ritmo livre, para que esse trabalho seja possível. Não somente deve se utilizar uma grande quantidade de ar, como é vital que a coluna de ar permaneça constante, tanto na subida como na descida, para se manter a qualidade do som.

Pacho Flores aconselha que os alunos façam esses exercícios cantando, em falsete, bem lentamente, para entenderem como é possível realizar essas mudanças com menos esforço. Ele recomenda também "estudar buscando uma afinação perfeita e aplicar frequentemente nas ligaduras glissandos, para poder encurtar as distâncias (FLORES, Pacho) (Fig. 7, exercício que resulta da expansão dos exercícios da Fig. 6). Quando o

\footnotetext{
15 Original: "Buzzing on the mouthpiece has many benefits if done with a systematic and observant approach. Because the mouthpiece offers less resistance than does the instrument, buzzing helps accustom the player to using more air. This greater airflow helps let the lips relax and vibrate more freely, producing a more resonant sound".

16 Original: "Playing the mouthpiece is great. And can be a big help improving sound, getting loose and warming up ... BUT... I play the mouthpiece, I don't buzz into it. A buzz type sound does come out of it though. There is confusion because I have been teaching 'Blow Don't Buzz' for years... If you buzz your lips to play you will sound like a beginner or a cat choking on a hair ball after smoking a pack of Camel straights".
} 
aluno atinge o seu limite, Pacho Flores adverte que, mesmo que a nota não tenha sido alcançada, é importante que o ar continue saindo.

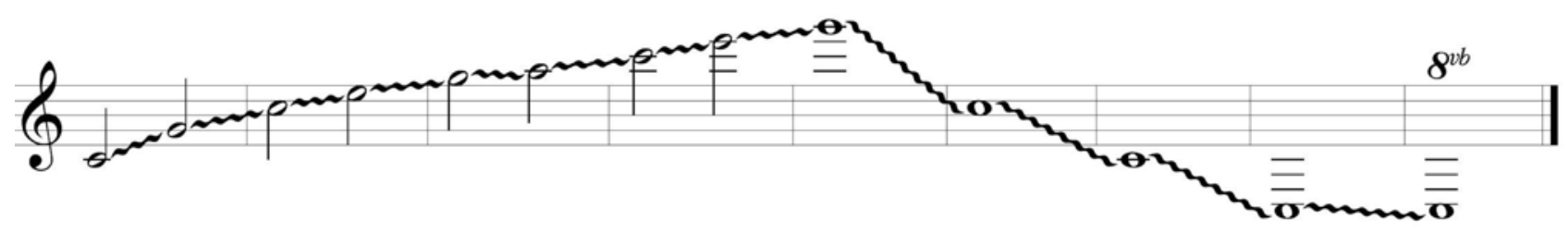

Fig. 7: Exercícios expandidos de vibração labial com bocal.

Fonte: Notações musicais feitas pelo autor.

Os dois primeiros compassos do exercício a seguir (Fig. 8) são tocados a tempo, já os compassos com glissando novamente com tempo livre.

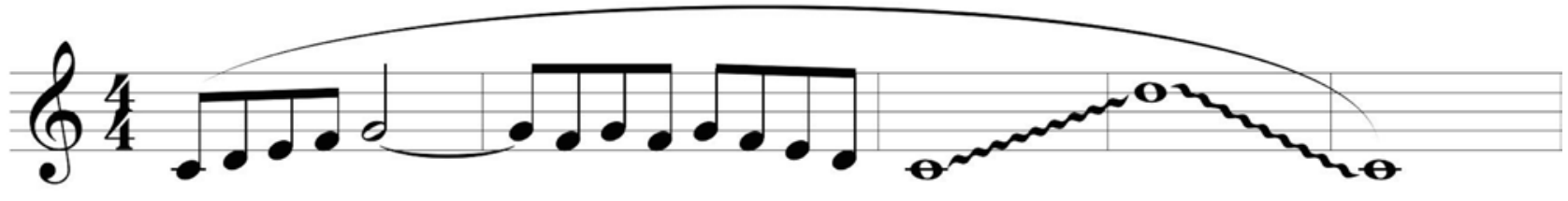

Fig. 8: Baseado no exercício de James Stamp, nos dois primeiros compassos, com variação ao final.

Fonte: Notações musicais feitas pelo autor.

\section{Notas pedais}

No trompete, as notas pedais são consideradas todas aquelas que se obtém abaixo do Fá\#2. São chamadas de pedais falsos as notas entre Fá2 e Réb2 (Fig. 9), por não pertencerem a nenhuma série harmônica possível em todas as combinações de válvulas. Os pedais naturais encontram-se entre o Dó2 e o Fá\#1, sendo as notas fundamentais da série harmônica de cada posição. Qualquer nota abaixo do Fá\#1 é chamada de duplo pedal.

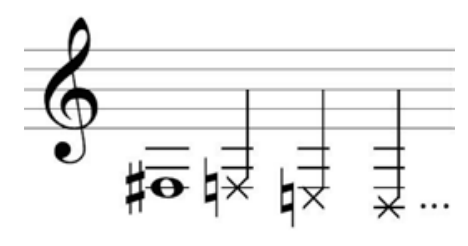

Fig. 9: Pedais falsos.

Fonte: Notações musicais feitas pelo autor.

Utilizada constantemente no repertório contemporâneo, a prática do registro é regular nos estudos diários de Pacho Flores por outros motivos: 
Pratico os pedais para ter a sensação de que estou utilizando bem o meu ar. Evidentemente os pedais são mais difíceis que o registro normal, por isso que, sempre que buscamos um bom som nas notas pedais, isso repercute diretamente no som do registro natural. (FLORES, Pacho).

Segundo Claude Gordon, a prática do registro pedal tem os seguintes benefícios: "corrigir a embocadura - e, portanto, ajudar no registro agudo -, permitir um grande domínio do instrumento, proporcionar mais força e fluência, ajudar os ataques e a precisão, desenvolver uma melhor vibração e resistência [e, finalmente, obter um] som grande em todos os registros" (GORDON, 1968, p.8) ${ }^{17}$. Apesar de ser um assunto bem menos polêmico que a prática da "abelhinha" sem bocal, ao observar os números obtidos entre os trompetistas pesquisados, nota-se que há um número significativo de instrumentistas que não praticam notas pedais regularmente $(57,89 \%$ dos profissionais e $69,23 \%$ dos estudantes).

O relato do conceituado trompetista Junior Galante, conhecido por seu domínio no registro extremo agudo do trompete, desmistifica a ideia de que para tocar agudos é preciso dominar o registro pedal. Ele revelou ter estudado "em um momento de pouquíssima maturidade os estudos de notas pedais, portanto não deu certo"18. Pacho Flores pratica vários outros exercícios no registro pedal (ver, por exemplo, Fig. 10 e 11).

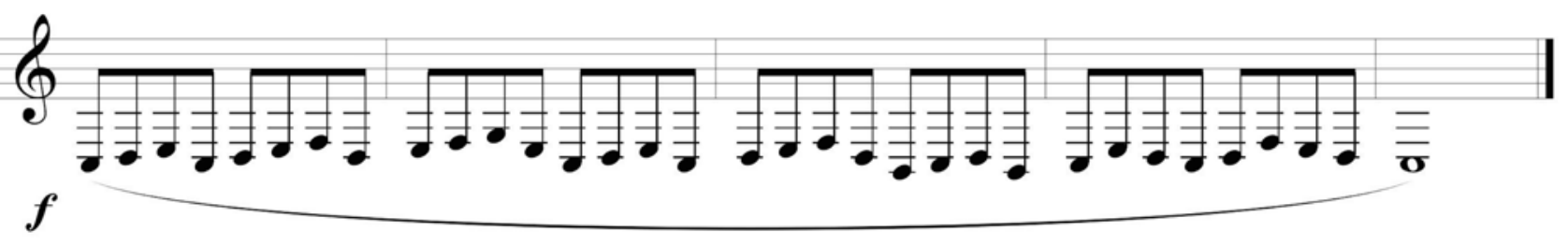

Fig. 10: Baseado no exercício n. 2 de H. Clarke, realizado uma oitava abaixo do original. Fonte: Notações musicais feitas pelo autor.

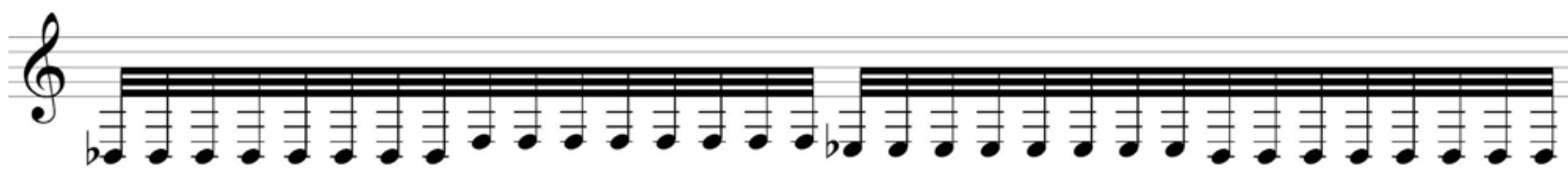

Fig. 11: Baseado no exercício n. 2 de H. Clarke, realizado uma oitava abaixo do original em staccato. Fonte: Notações musicais feitas pelo autor.

Após inúmeros exercícios no registro agudo, é apresentada uma atividade final com o objetivo de relaxamento (Fig. 12). A respeito da prática de pedais, Pacho Flores aconselha: "Não forçar as notas pedais e não abrir os lábios de forma desnecessária e, por último, relaxar a garganta o tanto que for possível" (FLORES, Pacho). Além dos exercícios envolvendo notas pedais, Pacho Flores realiza diversos exercícios com escalas

17 No original: "Correct your emboucher - therefore, help high register. Give you great command of your instrument. Give you more power and fluency. Aid your attack and sureness. Develop better vibration. Develop intervals and fluency. Bigger sound in all registers. Develop endurance".

18 Em conversa realizada via mensagem instantânea na rede social Facebook, em 30 de março de 2015. 
e arpejos com as mais variadas possibilidades de articulações. Em geral, iniciando no registro médio do instrumento, normalmente entre Dó3 e Dó4 e expandindo para os registros extremos.

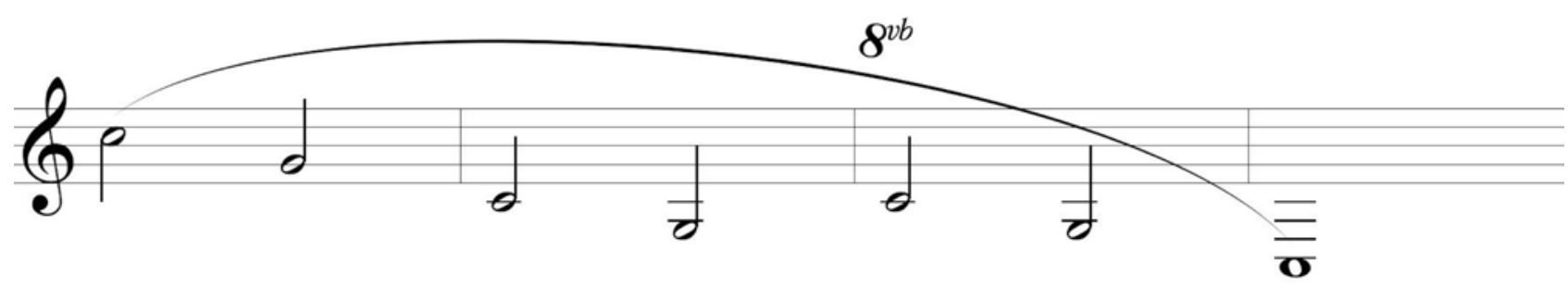

Fig. 12: Exercício para relaxamento labial. Fonte: Notações musicais feitas pelo autor.

\section{Considerações finais}

Ao analisar a prática diária de Pacho Flores, relacionando-a aos métodos tradicionais que o inspiraram e comparando-a com a prática realizada por trompetistas brasileiros, profissionais e estudantes, é possível verificar que a carga horária de estudos e os métodos utilizados são os mesmos na maioria dos casos. Entretanto, o trompetista venezuelano apresenta maior ênfase nos estudos de vibração labial e na prática de notas pedais. A transcrição dos exercícios por ele apresentados pode ajudar o desenvolvimento técnico de um trompetista por conterem as mais diversas variações sobre exercícios expostos nos métodos tradicionais.

A rotina de estudos aqui esboçada foi elaborada e serve ao trompetista Pacho Flores, o que, por si só, é de extrema relevância. Por outro lado, cabe ressaltar que, diante da individualidade e das demandas específicas, cada instrumentista, principalmente aquele que se encontra nas fases iniciais, deve ser acompanhado por um professor experiente. Além disso, embora não seja o foco do presente artigo, nesta fase inicial, recorrer aos métodos tradicionais de trompete - como os citados Arban, Clarke e Schlossberg - é sempre salutar.

Em tal contexto, tendo aqui se tratado da fase de "aquecimento" e da rotina de estudo de um trompetista, serão válidas pesquisas complementares que tratem de tais assuntos sobre a perspectiva de outros instrumentos da família dos metais, onde há bastante literatura sobre o assunto. O presente artigo não esgota o assunto, mas aponta os benefícios de pesquisas que se detenham em discutir os métodos de estudo e os recursos utilizados por instrumentistas renomados. Em tal contexto, faz-se necessária a elaboração de um estudo a respeito da utilização do processo criativo e dos seus benefícios na prática diária de Pacho Flores. Por outro lado, mais importante que supervalorizar os exercícios do trompetista venezuelano, os interessados em progredir do ponto de vista da técnica instrumental devem utilizar os elementos da tradição como ponto de partida para criar sua própria prática diária, de acordo com seu histórico e com suas necessidades. 


\section{Referências}

ARBAN, J. Batispte. Complete method: trumpet. Platinum Edition. New York: Carl Fischer, 2005. 386p.

CLARKE, Herbert L. Elementary studies for trumpet. New York: Carl Fischer, 1970. 56p. Technical studies for the cornet. New York: Carl Fischer, 1970. 53p.

ALENCAR, Thiago A. M. Di.; MATIAS, Karina F. S. Princípios Fisiológicos do Aquecimento e Alongamento Muscular na Atividade Esportiva Disponível em: http://www.scielo.br/ pdf/rbme/v16n3/15.pdf Acesso em: 28 mar. 2015.

EL SISTEMA. Disponível em: http://fundamusical.org.ve/el-sistema. Acesso em: 24 maio 2015.

EL SISTEMA. Impacto Social. Disponível em: http://fundamusical.org.ve/category/elsistema/impacto-social. Acesso em: 24 maio 2015.

GORDON, Claude. Physical Approach. New York: Ed. Carl Fischer, 1977. 64p.

Systematic approach to daily pratice for trumpet. New York: Carl Fischer, 1968. 128p.

PURTLE, Jeff. Claude Gordon's Approach by Jeff Purtle (2014). Disponível em https:// www.purtle.com/claude-gordon-approach. Acesso em: 12 mar. 2015.

SCHLOSSBERG, Max. Daily drills and technical studies for trumpet. New York: M. Baron, 1959. $60 p$.

SIMÕES, Naílson. Uma abordagem técnico-interpretativa e histórica da escola de trompete de Boston e sua influência no Brasil. Debates, n. 5. Rio de Janeiro: Cadernos do programa de Pós-Graduação em Música do Centro de Letras e Artes da Unirio, 2001.

STAMP, James. Warm-ups and studies. Vuarmarens: BIM, 1995. 34p.

THOMPSON, James. The buzzing book (2015). Disponível em: http://www. jamesthompsonmusic.com/TheBuzzingBook.php. Acesso em: 2 abr. 2015.

VIZZUTTI, Allen. Mouthpiece buzzing (2012). Disponível em: http://vizzutti.forumotion. com/t9-mouthpiece-buzzing. Acesso em: 2 abr. 2015. 
VAYÓN, Pablo J. Pacho Flores Trompetista. 2018. Disponível em: https://www. diariodesevilla.es/mapademusicas/Pacho_Flores-entrevista_0_1302770158.html. Acesso em: 29 jul. 2019.

MCKEY, Willy. Pacho Flores: uno de los mejores trompetistas del mundo es venezolano. 2013. Disponivel em: http://historico.prodavinci.com/2013/08/26/artes/ pacho-flores-uno-de-los-mejores-trompetistas-del-mundo-es-venezolano-porwilly-mckey/. Acesso em: 29 jul. 2019. 